\title{
RESEARCH PAPER \\ WATER, SANITATION AND HYGIENE IN COMMUNITY- BASED CARE: IMPLICATIONS FOR WELLBEING FOR PEOPLE LIVING WITH HIV/AIDS/TB IN DURBAN, SOUTH AFRICA
}

\author{
${ }^{1}$ C. Mulopo and O. Akintola ${ }^{1,2}$ \\ ${ }^{1}$ Health Promotion Programme, Discipline of Psychology \\ School of Applied Human Sciences, University of KwaZulu-Natal \\ ${ }^{2}$ School of Human and Social Development, Nipissing University, North Bay, Canada \\ Corresponding author: akintolao@ukzn.ac.za
}

\begin{abstract}
Majority of the HIVIAIDS patients in South Africa receive health care services at home. However, limited studies have been conducted to examine the water, sanitation and hygiene (WASH) situation in the homes of the care receivers and its impact on community-based care. The main objective of this study was to explore community health workers $(\mathrm{CHW})$ perceptions on WASH in home-based care and the implications on people living with HIV/AIDS/TB, their family members and the CHW. Participants for this qualitative study were drawn from four community home-based care organizations in four marginalized communities in Durban providing care to HIV/AIDS/TB clients. Data was collected using participant observation of care-giving activities; semi-structured interviews with five home-based care project managers from the organizations and five focus group discussions with a total of $49 \mathrm{CHW}$. The study revealed that $\mathrm{CHW}$ had limited access to protective materials such as gloves and aprons and therefore tended to avoid carrying out activities that could help maintain proper hygiene in the homes for fear of infection. There was limited and unreliable access to water supply. $\mathrm{CHW}$ had to fetch water from immediate neighbours or surrounding areas and this created a time burden for caregivers taking away the time spent with patients. Inadequate access to water influences sanitation and hygiene, and this affects the work of $\mathrm{CHW}$. Government needs to respond promptly to the water and sanitation needs of marginalized communities with limited resources. The findings of the study had implications for policy on WASH and community-based care in low in-come communities.
\end{abstract}

Keywords: WASH, HIVIAIDS, Community-based care, Community health workers, Care-givers

\section{INTRODUCTION}

Unsafe and insufficient water, poor sanitation and hygiene are some of the factors contributing to poor health in low and middle-income countries (World Health Organization [WHO],
Public Health England [PHE], and United Nations Office for Disaster Risk Reduction [UNISDR], 2011). They can result in constrained medical treatment in health services and increase a community's vulnerability 


\section{3}

\section{Mulopo and Akintola}

(Montgomery and Elimelech, 2007). It is estimated that over 2 billion of the world's population do not have access to adequate sanitation, with sub-Saharan Africa having the highest proportion of 30\% (WHO and UNICEF, 2006). In sub-Saharan Africa 8 out of 10 people without improved water live in rural areas and 9 out of 10 people in rural areas practice open defecation (WHO, 2015). Approximately 115 people die every hour from diseases resulting from poor sanitation, poor hygiene and contaminated water in Africa (WHO and UNICEF, 2006). In South Africa, close to 6 million people do not have access to safe drinking water (Department of Water Affairs and Forestry [DWAF], 2008). Furthermore, approximately 1.4 million households do not have access to a sanitation service and 3.8 million households have access but it is inadequate (DWAF, 2012). In addition to the WASH challenges that the world is currently facing, one of the most devastating diseases infecting people all over the world is HIV and AIDS (Joint United Nation Programme for HIV/AIDS [UNAIDS], 2010).

South Africa has the highest number of individuals living with HIV/AIDS in the world and in Sub-Saharan Africa (UNAIDS, 2013). The national estimate of people living with HIV in South Africa is 6,300,000 (UNAIDS, 2013). According to Akintola (2011), the high HIV prevalence in South Africa has resulted in large numbers of patients seeking care at public hospitals. Many of these hospitals cannot cope with the high influx of patients, so they send patients with HIV/AIDS home to be cared for by their family members (Potgieter and du Preez, 2012; Akintola, 2006). Home and community-based care is one of the interventions to deal with the HIV epidemic in South Africa (Singh et al, 2011). People living with HIV/ AIDS are vulnerable because their need for clean water and good sanitation and hygiene practices increase as they struggle to cope with the disease (Water Aid report, 2010). Therefore it is crucial for individuals in home-based care to have access to clean water, and practice proper sanitation and hygiene. In home and community-based care, water is used to bath patients with HIV/AIDS, wash soiled clothing and linen, keep the home environment clean, take medication, cook food, and adopt hygienic practices to prevent the spread of infectious diseases (Yallew et al., 2012). Unfortunately, access to potable water, safe sanitation and good hygiene may become more difficult for people living with HIV/AIDS due to their declining physical health and worsening economic status (Yallew et al., 2012). A study conducted in Botswana found that $66 \%$ of caregivers indicated that water shortage undermined their daily activities (Ngwenya and Kgathi, 2006). Also, a study conducted by Akintola and Hangulu (2014) in South Africa found out that poor sanitation and hygiene practices in homes and community-based care presented a risk for TB and HIV transmission. Similarly, Blinkhoff, et al (2001) in their study also found that home and community-based care were associated with the high risk of infection of HIV/AIDS and TB.

Potgieter et al., (2007) found, in a study conducted in Limpopo South Africa that the problems associated with WASH served as a barrier to the effective treatment of people living with HIV/AIDS in home-based care. In addition, one of the key findings by Potgieter and du Preez's (2012) study was that people living with HIV and AIDS and households affected by HIV and AIDS had substantially greater needs for potable water, safe sanitation and good hygiene. Ngwenya and Kgathi (2006) found that reduced access to water supplies among households providing care and caregivers affected their day -to-day activities negatively. Although these studies provide some information about WASH and HIV and AIDS care, they do not shed enough light on WASH in home and community-based care. This study sought to explore caregivers' perspectives about WASH in home and community-based care.

\section{METHODOLOGY}

The study employed a range of research methods including participant observation, in-depth 
qualitative interviews as well as focus group discussions. The explorative nature of qualitative research design was seen as most appropriate because of its flexibility to permit the consideration of different aspects to the phenomena (Neuman, 2014).

\section{Research context}

The research study was conducted in four marginalized peri-urban communities in the Durban Metropolis where four non-profit organisations were engaged in home and community based care for HIV/AIDs/TB patients. The data was collected over a period of four months (November 2014 - February 2015).

\section{Study participants}

Prior to the data collection, ethical approval was granted by the Human and Social Sciences Research Ethics Committee of the University of KwaZulu-Natal, Durban, South Africa. Five indepth interviews were conducted with project managers; one each from three organisations and two from one organisation. In one organisation the founder and an appointed project manager to whom CHWs reported to were interviewed. All in-depth interviews were conducted in English. Furthermore, five focus group discussions in IsiZulu language with 49 community health workers were conducted. Each focus group consisted of 5-12 participants. This study sought the perspectives of CHWs because they have first-hand experience regarding the provision of care to patients and their related situations with WASH. In addition extensive field notes and careful observations were made during the field visits.

\section{DATA ANALYSIS METHODS}

All data collected in IsiZulu was translated and transcribed to English by a trained IsiZulu speaking research assistant. Data was analysed following the six steps of thematic analysis described by Braun and Clarke (2006). Three main themes emerged from the data:

1) Acessibility and availability of water in home and community-based care;
2) The relevance of water in relation to sanitation; and

3) The need for water to maintain good hygiene.

\section{FINDINGS}

Socio-demographic profile of community health workers

The total sample of community health workers was $49(n=49)$. All community health workers were female. Most of the CHW were Christians. Their ages ranged from 20-58 years old. They all had worked in the community-based organization for not less than 6 months and the longest serving participant had worked for 13 years. CHW did not receive remuneration for their work, however some did receive a stipend at the end of the month and this was also dependent on the availability of funds in the organization.

Accessibility/availability of water in the homes for community based care

Access to water in community-based care is crucial. Water is necessary for infection control as well as to maintain hygiene in households that have people living with HIV/AIDS (PLWHA). In the focus group discussion it became clear that access to water was a challenge. Participants in focus group 1 indicated:

"...we're given taps in our communities ...but you find that there'll be a time where there is no water, you can't get water maybe for a month or a few weeks and the person with HIV suffers". Community health workers need water in order for them to care for their patients. Unavailability of water hinders them from performing their duties. In the words of the CHW.

" it happens that I need to bathe a patient but the water is often muddled and polluted, and I end up having to leave without bathing the patient” (Focus group 2).

This was a clear indication from participants that they did not have water readily available to them. 
It is also the duty of the CHW to ensure that their patients take the medications while under their care. However, unreliable water supply interferes with the routine of medication intake with some patients not being able to take their medications when they are supposed to because they did not have access to water.

"The patient might need to take pills, let's say its 8 O'clock everyday, however sometimes they are unable to take medication at that time because there is no running water and the only available water stored in the house is dirty" (Focus group 1).

Patients end up not taking their TB or antiretroviral medication when they are supposed to, and this has serious consequences for them. This can result in the patient becoming drug resistant and worsening the health of the patient.

CHW therefore have to go and fetch water for the patients in order for them to perform their duties as well as meet the patients' needs. However, this creates a time burden for the caregiver as they have a lot of patients to care for.

A project manager from one of the organizations said "The challenge is that it takes a lot of time for the CHW to go and fetch water and this is a problem because they have a lot of patients to attend to. Fetching water sometimes prevents them from seeing other patients" (Project Manager 5).

Moreover going to fetch water takes away from the time spent with the patient and one of the project managers feared that while the $\mathrm{CHW}$ is away to fetch water, patients left alone may hurt themselves. She went on to say,

"standing in the queue for so long and leaving the patient unattended for so long. A lot of things can happen during the absence of the care-giver because some of the patients are so ill they can't move or do anything. They could fall off the bed or anything could actually happen. Sometimes caregivers resort to locking their patients in the rooms, without proper ventilation and access to toilets" (Project manager 4).

The relevance of water in relation to sanitation

Water is necessary to keep the homes clean as well as to clean the toilets in order to reduce the transmission of opportunistic diseases. Patients suffering from AIDS experience loss of control in their bowel movement, as a result they defeecate and urinate on themselves. It became apparent in the focus group discussions that there was a great need for water in households with PLWHA as the community health workers described the conditions in the patients' homes as a result of inadequate water.

"It's different for every household, sometimes you'd arrive and find a sense of cleanliness but in other houses it doesn't exist, and so you find that houses are not cleaned and patients are not washed because there is no water"(Focus group 4).

The conditions in the homes can be so appalling with patients living in unhygienic conditions and the patients relying on the $\mathrm{CHW}$ to maintain good hygienic conditions with little or no support from family members of the patients.

"Sometimes when you can get to an elderly patient's home whom you only see once a week and you find that in their room there is a plastic bag filled with disposable nappies, hanging for days in the same room as the patient. This is so worrying because it is not a good thing at all to have such conditions" (Focus group 2).

CHW need water to clean the homes of the patients. They need to clean up the vomit from the patients as well as the food left by the patients since most patients suffer from loss of appetite and they are sometimes too weak to feed themselves.

"Sometimes a patient is given a meal in the evening and he/she eats only a portion of it. The patient leaves the rest of the food on a chair and by the next day the leftover food is 
infested with ants and cockroaches" (Focus group 3).

In order to save water, toilets are only flushed when a member of PLWHA household bathes or when the caregiver fetches water to bathe the patient, the water from the bath is then used to flush the toilet. If nobody bathes or if the caregiver was not able to bath the patients then the toilet would not be flushed.

"You find that the households with four rooms have flushing toilets. When they experience water shortages the toilets are dirty, because there isn't any water. In situations where you are assisting a patient, you experience challenges because there is no water. As a CHW I am forced to use water that I bathed the patient with to flush the toilet and if no one left his or her bathing water then there is no water to flush the toilet" (Focus group 3).

\section{The need for water to maintain hygiene}

One way through which HIV is transmitted is by direct contact with body fluids of an individual infected with the virus. Community caregivers come into contact with body excretions of PLWHA in their day-to-day activities.

"While wearing gloves you take the "powa" (a bucket like container used to defecate in) containing the feces and empty it out into the toilet" (Focus group 2).

Hence CHWs are susceptible to the risk of contracting the HIV Virus through their work. There is therefore the need for protective equipment as well as water to maintain hygiene in community-based care in order to ensure infection control.

"Sometimes you find that the patients you are looking after have soiled themselves and you would need to help get them clean. It's difficult to leave people who have soiled themselves without cleaning them just because there is no water." (Focus group 4).

Since most HIV/AIDS patients are co-infected with tuberculosis (TB), which is an airborne disease, CHW also need masks to protect themselves from getting infected. However, homebased care organizations rely on donors and government to provide them with protective equipment and sometimes it happens that the organization does not have all the necessary equipment resulting in caregivers having to care for patients with $\mathrm{TB}$ without masks at a great risk to their health.

\footnotetext{
"In our work with people infected with TB, we usually go to them even if we do not have protective material. But they (Organisation) help us by going to check us up for TB regularly" (Focus group 4).
}

CHW need water to maintain hygiene as they move from home to home and patient to patient for infection control purposes.

"We use gloves and little plastic aprons to protect ourselves, because as I have mentioned earlier on we give bed bathes so we use gloves to handle the patients because some have bedsores and rashes. It is important for us to wash our hands when we are done so that we do not easily contract the sickness" (Focus group 1).

\section{DISCUSSION}

The findings show that limited water supply in marginalized communities has adverse ramifications for the wellbeing of individuals living with HIV/AIDS/TB. Although the Municipality has made efforts to provide low-income communities with communal taps (Manase et al, 2009), these taps are not regularly checked or maintained which makes them get damaged. Some taps have been vandalized by community members and have not been replaced. This has resulted in community health workers and PLWHA having to walk long distances in order to access water. Reduced access to water worsens the burden of caregivers; this finding is consistent with Ngwenya and Kgathi (2006) who concluded that reduced access to water brought about a time burden for caregivers. 
The study found that there was a great need for water in households that have PLWHA. Nwenya and Kgathi (2006) found that households with PLWHA use more water. Households that have patients living with HIV/AIDS need water to clean the patient's vomit, to bathe the patients, wash soiled clothing and linen and keep the home environment clean. Since individuals living with HIV/AIDS have weak immune systems, keeping the home environment and the toilets clean is necessary to reduce transmission of opportunistic diseases, and availability of water helps to maintain a high level of cleanliness.

The findings also revealed the need for protective equipment for community health workers. Community health workers are continuously exposed to the body fluids of PLWHA in their daily activities and they sometimes work without protective equipment (Akintola and Hangulu, 2014). The government needs to intervene and ensure that there is a continuous supply of protective material to organizations offering care to PLWHA. This will help households and community health workers to maintain hygiene in community based care.

\section{CONCLUSION}

This study reveals the importance of WASH services in community-based care. The study has highlighted the perspectives of $\mathrm{CHW}$ on WASH in community-based care. The government needs to address the issues relating to water and sanitation in low-income communities. One way of doing this would be for the department of health to collaborate with the department of water and sanitation to ensure that households with PLWHA in particular are supplied with sufficient water.

\section{ACKNOWLEDGEMENTS}

Some of the ideas that inspired this study were first presented by $\mathrm{OA}$ at the United Nations University-Institute for Water, Environment and Health [UNU-INWEH] Conference on WASH and Wellbeing, Hamilton, Canada (25 \& 26 November, 2013). This paper is part of
CM's Master's Research Dissertation supervised by OA. An earlier version of the paper was presented by CM at the 2nd SNOWS Science Conference for Early Career Scientists working in Africa, Kumasi, Ghana (18-20 May). The authors are greatly indebted to the community health workers and programme managers who participated in the study. We will also like to thank participants at both meetings for their feedback and suggestions.CM would like to thank the Wellcome Trust, UK for supporting her participation in the SNOW conference.

\section{REFERENCES}

Akintola, O. and Hangulu, L. (2014). Infection control in home-based care for people living with HIV/AIDS/TB in South Africa: An exploratory study. Global Public Health, 9(4): $382-393$.

Akintola, O. (2011). Home-based care and social capital: Exploring the role of social capital in resource creation and access. ResponseAbility in the Era of AIDS: Building SocialCapital in Community Care and Support. Bloemfontein, South Africa: AFRICAN SUN MEDIA, 227-243.

Akintola, O. (2006). Gendered home-based care in South Africa: more trouble for the troubled. African Journal of AIDS Research,5(3): 237-247.

Blinkhoff, P., Bukanga, E., Syamalevwe, B. and Williams, G. (2001). Under the $\mathrm{Mu}$ pundu Tree: Volunteers in Home Care for People with HIV/AIDS and TB in Zambia Copperbelt. London, UK: Strategies for Hope Series No 14, ActionAid

Braun, V. and Clarke, V. (2006). Using thematic analysis in psychology. Qualitative Research in Psychology, 3(2): 77-101.

DWAF (2012). Sanitation Services -Quality of Sanitation in South Africa: Report on the Status Of Sanitation Services in South Afr- 
Community health workers $(\mathrm{CHW})$ perceptions on WASH ... 28

ica.

DWAF (2008).Water and Sanitation Coverage in South Africa. Department of Water Affairs and Forestry.

Neuman, W. L. (2014). Social research methods: qualitative and quantitative approaches. Harlow: Pearson.

Manase, G., Nkuna, Z. and Ngorima, E. (2009). Using water and sanitation as an entry point to fight poverty and respond to HIV/AIDS: The case of Isulabasha Small Medium Enterprise. Physics and Chemistry of the Earth, Parts A/B/C, 34(13): 866-873.

Montgomery, M. A. and Elimelech, M. (2007). Water and sanitation in developing countries: including health in the equation. Environmental Science \& Technology, 41(1): 17-24.

Ngwenya, B. N. and Kgathi, D. L. (2006). HIV/ AIDS and access to water: a case study of home-based care in Ngamiland, Botswana. Physics and Chemistry of the Earth, Parts A/ $B / C, 31(15)$ : 669-680.

Potgieter, N. and du Preez, M. (2012). Health impact of water, sanitation and hygiene services in relation to home-based care for people living with HIV and AIDS in the Limpopo Province, South Africa. WRC Report.

Potgieter, N., Koekemoer, R. and Jagals, P. (2007). A pilot assessment of water, sanitation, hygiene and home-based care services for people living with HIV/AIDS in rural and peri-urban communities in South Africa. Water Science and Technology, 56(5): 125-131.

Singh, D., Chaudoir, S. R., Escobar, M. C. and Kalichman, S. (2011). Stigma, burden, social support, and willingness to care among care- givers of PLWHA in home-based care in South Africa. AIDS Care, 23(7): 839-845.

UNAIDS (2010). UNAIDS report on the global AIDS epidemic: Geneva

UNAIDS (2013). Global report on the global AIDS epidemic, Retrieved on $18^{\text {th }}$ August 2015 from: http://www.unaids.org/sites/ default/files/en/media/unaids/contentassets/ documents/epidemiology/2013/gr2013/ UNAIDS_Global_Report_2013_

Water Aid Report (2010). Access to water, sanitation and hygiene for people living with HIV and AIDS: A cross-sectional study in Nepal

WHO and UNICEF. (2006). Meeting the MDG drinking water and sanitation target, the urban and rural challenge of the decade. Retrieved from: http://www.who.int/ water_sanitation_health/monitoring/ jmpfinal.pdf

WHO and PHE and UNISDR (2011). Disaster Risk Management for health. Water, Sanitation and hygiene, Retrieved on 14th April from: http://www.who.int/hac/events/ drm_fact_sheet_wash.pdf

WHO (2015). Key Facts from JMP 2015 Report, Retrieved on $15^{\text {th }}$ June 2015 from: http://www.who.int/water_sanitation_health/ monitoring/jmp-2015-key-facts/en/

Yallew, W. W., Terefe, M. W., Herchline, T. E., Sharma, H. R., Bitew, B. D., Kifle, M. W. and Adane, M. M. (2012). Assessment of water, sanitation, and hygiene practice and associated factors among people living with HIV/AIDS home based care services in Gondar city, Ethiopia. BMC Public Health, 12(1): $1-10$ 